Article

\title{
Structure Determination of Au on Pt(111) Surface: LEED, STM and DFT Study
}

\author{
Katarzyna Krupski ${ }^{1}$, Marco Moors ${ }^{2}$, Pawel Jóźwik ${ }^{3}$, Tomasz Kobiela ${ }^{4}$ and \\ Aleksander Krupski ${ }^{1,3,5, *}$
}

1 Department of Physics, University of Warwick, Coventry CV4 7AL, UK;

E-Mail: k.j.krupski@warwick.ac.uk

2 Peter Grünberg Institut, Forschungszentrum Jülich, Wilhelm-Johnen-Str., 52425 Jülich, Germany; E-Mail: m.moors@fz-juelich.de

3 Department of Advanced Materials and Technologies, Faculty of Advanced Technologies and Chemistry, Military University of Technology, Kaliskiego 2 Str., 00-908 Warszawa, Poland;

E-Mail: pjozwik@wat.edu.pl

4 Faculty of Chemistry, Warsaw University of Technology, ul. Noakowskiego 3, 00-664 Warsaw, Poland; E-Mail: kobiela@ch.pw.edu.pl

5 Faculty of Science, SEES, University of Portsmouth, Portsmouth PO1 3QL, UK

* Author to whom correspondence should be addressed; E-Mail: aleksander.krupski@port.ac.uk.

Academic Editor: Marco Salerno

Received: 20 January 2015 / Accepted: 8 May 2015 / Published: 27 May 2015

\begin{abstract}
Low-energy electron diffraction (LEED), scanning tunneling microscopy (STM) and density functional theory (DFT) calculations have been used to investigate the atomic and electronic structure of gold deposited (between 0.8 and 1.0 monolayer) on the $\operatorname{Pt}(111)$ face in ultrahigh vacuum at room temperature. The analysis of LEED and STM measurements indicates two-dimensional growth of the first Au monolayer. Change of the measured surface lattice constant equal to $2.80 \AA$ after Au adsorption was not observed. Based on DFT, the distance between the nearest atoms in the case of bare $\operatorname{Pt}(111)$ and $\mathrm{Au} / \mathrm{Pt}(111)$ surface is equal to $2.83 \AA$, which gives $1 \%$ difference in comparison with STM values. The first and second interlayer spacing of the clean $\operatorname{Pt}(111)$ surface are expanded by $+0.87 \%$ and contracted by $-0.43 \%$, respectively. The adsorption energy of the Au atom on the $\operatorname{Pt}(111)$ surface is dependent on the adsorption position, and there is a preference for a hollow $f c c$ site. For the $\mathrm{Au} / \mathrm{Pt}(111)$ surface, the top interlayer spacing is expanded by $+2.16 \%$ with respect to the ideal bulk value. Changes in the electronic properties of the $\mathrm{Au} / \mathrm{Pt}(111)$
\end{abstract}


system below the Fermi level connected to the interaction of Au atoms with $\operatorname{Pt}(111)$ surface are observed.

Keywords: density functional theory calculations; scanning tunneling microscopy; low-energy electron diffraction; surface structure; metallic surfaces; gold; platinum; metal-metal interfaces; low index single crystal surface

\section{Introduction}

A large number of studies on epitaxy have been carried out for many years. Ultra-thin epitaxial film systems exhibit a variety of interesting properties due to the strong correlation between the electronic structure of the film and its morphology, strain, and defect structure [1-10]. Structural studies of $f c c / f c c$ systems provide a great deal of information on the connection between the geometrical properties of the adsorbed atomic layers and the atomic arrangements of the substrates. Various fields are concerned with epitaxial growth; these range from basic research on the growth mechanism of thin films to advanced research on the development of devices. Platinum is widely used as a catalyst in the chemical and petrochemical industries [11,12]. For example, in oil refineries, platinum catalysts are employed in processes that involve the reforming of paraffin and the hydrogenation of unsaturated hydrocarbons [11-14].

The clean $\operatorname{Pt}(111)$ surface itself has been the subject of several structural determinations with Low Energy Electron Diffraction (LEED) [15-23], medium energy ion scattering (MEIS) [24], high energy ion scattering (HEIS) [25] and surface X-ray diffraction (SXRD) [26,27]. Differently from the other noble metal (111) surfaces, clean Pt(111) normally has an unreconstructed bulk-periodic surface [23,28-30]. Adams et al. [18] found the first layer spacing to be possible to expand by $0.04 \pm$ $0.10 \AA$, while Hayek et al. [21] found an unrelaxed surface with $0.05 \AA$. Materer et al. [23] found the first and second interlayer spacing expanded by $0.04 \pm 0.10 \AA$ and $0.005 \pm 0.03 \AA$, respectively. MEIS and HEIS experiments [24,25] support the LEED results. Namely, the ion scattering data indicate that the $\operatorname{Pt}(111)$ structure deviates from the bulk geometry by a possible small outward expansion of the top interlayer spacing of $0.03 \pm 0.02 \AA[24]$ or $0.03 \pm 0.02 \AA$ [25]. No deviation from the bulk position was found in the direction parallel to the surface, with a small accuracy of about $0.01 \pm 0.02 \AA$. The surface geometry of clean $\operatorname{Pt}(111)$ has been the subject of surface X-ray diffraction investigations [26]. These investigations gave an outward relaxation of the topmost layer of $0.045 \pm 0.005 \AA(+2.0 \%)$ with respect to the ideal bulk termination.

Properties of ultrathin gold layers deposited on the $\operatorname{Pt}(111)$ face were investigated in a number of works [31-42]. Studies on single crystalline Au-Pt(111) model surfaces, for instance, have provided detailed information on the catalytic properties of these surfaces [31-33]. Davies et al. [31] studied the growth and chemisorptive properties of gold and silver monolayers on platinum (111) and (553) single crystal surfaces using Auger electron spectroscopy (AES), LEED, and temperature-programmed desorption (TPD). The AES results suggested that the growth of Au proceeds via a Stranski-Krastanov mechanism at room temperature, and that at temperatures above $800 \mathrm{~K}$ gold dissolves into the Pt crystal bulk. No extra LEED order spots or spot streaking was observed. In contrast, Shatler et al. [32] with the use of AES, LEED, and TPD found that deposition of gold on $\operatorname{Pt}(111)$ near $\mathrm{T}=300 \mathrm{~K}$ indicates a 
layer-by-layer (Frank-van der Merwe) growth mechanism up to three gold monolayers. The analysis of AES measurements showed that two-dimensional islands growth below one monolayer took place. Furthermore, with increasing coverage, the gold islands grew until the monolayer is completed, before the second layer begins to form. In additional studies by Sachtler et al. [33], the activity for conversion of n-hexane as a function of Au surface concentration on $\mathrm{Pt}(111)$ was monitored. The Au-covered crystal was then annealed at elevated temperatures to allow Au intermixing with the Pt substrate. The formed Au-Pt(111) surface alloy showed a much higher activity for $\mathrm{n}$-hexane isomerization than pure Pt. Moreover, it has been reported that $\mathrm{Au}$ in a dispersed state exhibits a high activity for some reactions at low temperatures (e.g., $\mathrm{CO}$ oxidation) [35] and that this feature depends on the preparation conditions, size and shape of the $\mathrm{Au}$ nanostructures [36]. Adsorption experiments with $\mathrm{CO}$ as a titration agent showed a significantly lower affinity of the Au-Pt surface alloy in comparison to the clean $\mathrm{Pt}$ surface [37]. Salmeron et al. [38] used photoelectron spectroscopy techniques (UPS (ultraviolet) and XPS (X-ray)), LEED and AES to study the electronic structure of Au and Ag overlayers deposited on $\operatorname{Pt}(111), \operatorname{Pt}(100)$, and $\mathrm{Pt}(997)$. Between 0 and 1 monolayer, the valence bands of Au and Ag show changes in the form of shifts of the most tightly bound peaks and the appearance of the new structures around a coverage $\left(\theta_{\mathrm{Au}}\right)$ of one monolayer. The $\mathrm{Au} 5 d_{3 / 2}$ peak shifts $0.6 \mathrm{eV}$ towards higher binding energies when coverage varies from 0.1 to 1 monolayer and $0.5 \mathrm{eV}$ more when coverage varies from one to six monolayers. These shifts are explained as due to the changing contributions of the Au atoms in island edges for surface $\left(\theta_{\mathrm{Au}}<1\right)$ monolayer and bulk $\left(\theta_{\mathrm{Au}}>1\right)$ coordination positions. Using AES, they found that gold on $\operatorname{Pt}(111)$ grows layer-by-layer. Below $\theta_{\mathrm{Au}}<1$, no extra LEED spots were observed. In addition, the work function decreased upon gold deposition from its initial value of $6.08 \pm 0.15 \mathrm{eV}$ for clean $\mathrm{Pt}(111)$ down to $5.8 \pm 0.15 \mathrm{eV}$. That value was reached at the monolayer and remained constant thereafter up to five monolayers and is clearly larger than the $5.31 \mathrm{eV}$ value reported by Potter et al. [43] for bulk $\mathrm{Au}(111)$. The work function for the $\mathrm{Pt}(111)$ surface compares only fairly with that reported by Ertl et al. [44] of $6.40 \mathrm{eV}$. Its smaller value might reflect a less perfect surface with larger number of residual steps. It should be pointed out here that $\operatorname{Pt}(111)$ surface presents the highest work function value among other metals surfaces. Vogt et al. [39] studied $\mathrm{Au} / \mathrm{Pt}(111)$ system by spin-, angle- and energy-resolved photoemission with normal incident circularly polarized synchrotron radiation of BESSY and normal photoelectron emission for different $\mathrm{Au}$ coverages. The prepared layers were characterized by AES and LEED and turned out to grow up two-dimensionally and epitaxially. LEED spots did not show any changes in geometry during the evaporation time up to the coverage of a thick $\mathrm{Au}$ layer [39]. Later, the electrodeposition of $\mathrm{Au}$ on $\mathrm{Pt}(111)$ from electrolytes containing $\mu \mathrm{M}$ concentrations of $\mathrm{AuCl}_{4}^{-}$was investigated by in situ electrochemical scanning tunneling microscopy (EC-STM) by Sibert et al. [41,42]. Under conditions of high Au surface mobility, multilayer growth proceeds via a typical Stranski-Krastanov growth mode, with layer-by-layer growth of a pseudomorphic Au film up to two monolayers and three-dimensional growth of structurally relaxed islands at higher coverage, indicating thermodynamic control under these conditions.

In the present work, in order to study the structural and electronic properties during the initial adsorption process of gold on $\mathrm{Pt}(111)$ surface at room temperature, we have performed low-energy electron diffraction, scanning tunneling microscopy measurements in ultrahigh vacuum and density functional theory calculations with the use of CASTEP code. 


\section{Experimental Details}

The measurements were carried out in a stainless steel ultra-high vacuum chamber with a base pressure of $2.0 \times 10^{-8} \mathrm{~Pa}$. The chamber was equipped with a reverse-view LEED optics, which was used for low-energy electron diffraction measurements, and also with a variable-temperature scanning tunneling microscopy stage. The Pt(111) single crystal was supplied by MaTeck [45]. The surface of the $\mathrm{Pt}(111)$ single crystal was cleaned by repeated cycles of sputtering with $3 \mathrm{keV}$ Argon ions at $\mathrm{T}=300 \mathrm{~K}$ and annealing at $\mathrm{T}=1100 \mathrm{~K}$. After annealing at $1100 \mathrm{~K}$, the residual carbon was removed in $7.0 \times 10^{-4} \mathrm{~Pa}$ of oxygen, followed by desorption of any remaining oxygen at $1200 \mathrm{~K}$. This procedure was repeated until the LEED pattern of a clean Pt(111) surface with sharp spots and low background was obtained. The deposition of $\mathrm{Au}$ (99.999\%) on the $\mathrm{Pt}(111)$ sample was achieved by vaporization from a Knudsen cell and the coverage of gold was determined via STM. Film coverages are described in monolayers (ML), where a $1 \mathrm{ML} \operatorname{Pt}(111)$ film corresponds to an atomic packing density of $1.503 \times 10^{15}$ atoms $/ \mathrm{cm}^{2}$ obtained from a bulk lattice constant apt $=3.9239 \AA$ [46] (for comparison the atomic packing density of $\mathrm{Au}(111)$ equals $1.387 \times 10^{15}$ atoms $/ \mathrm{cm}^{2}$ for $\mathrm{aAu}=4.0785 \AA$ [46]). This cell had been constructed from an $\mathrm{Al}_{2} \mathrm{O}_{3}$ crucible from Friatec [47] with a diameter of $5 \mathrm{~mm}$. It was filled with a $0.5 \mathrm{~mm}$ thick Au wire from Goodfellow [48] and closed by a two-hole ceramic. The Knudsen cell was heated by a tungsten wire from Goodfellow (diameter $0.3 \mathrm{~mm}$ ) wound around the crucible and thermally shielded by a water-cooled jacket. In order to control the deposition time, a rotatable shutter was placed in front of the cell opening. The working pressure during Au deposition was below $1.0 \times 10^{-7} \mathrm{~Pa}$. All STM measurements were performed with the use of electrochemically etched W (99.99\%) tips (diameter $0.5 \mathrm{~mm}$, length $3.5 \mathrm{~mm}$ ). For the potassium hydroxide electrolyte, a $4 \mathrm{~V}_{\mathrm{p}-\mathrm{p}}$ square wave voltage $(f=100 \mathrm{~Hz})$ was applied to the tip. In the electrochemical cell, a tungsten wire is used as the working electrode (anode) and a Pt (99.999\%) loop (diameter $10 \mathrm{~mm}$ ) is used as the counter electrode (cathode). A $3 \mathrm{M} \mathrm{KOH}$ solution from Sigma Aldrich [49] is used as the electrolyte. The following reactions take place:

Cathode Pt (Reduction Reaction):

$$
6 e^{-}+6 \mathrm{~K}^{+}+6 \mathrm{H}_{2} \mathrm{O}+\mathrm{Pt}_{\text {CATAlysts }} \rightarrow 6 \mathrm{KOH}+3 \mathrm{H}_{2}+\mathrm{Pt}_{\text {CATAlysts }}
$$

Anode W (Oxidation Reaction):

$$
\begin{gathered}
\mathrm{W} \rightarrow \mathrm{W}^{6+}+6 e^{-} \\
\mathrm{W}^{6+}+6 \mathrm{KOH} \rightarrow \mathrm{W}\left(\mathrm{OH}_{b}+6 \mathrm{~K}^{+}\right.
\end{gathered}
$$

Total Reaction:

$$
\mathrm{W}+6 \mathrm{H}_{2} \mathrm{O}+6 \mathrm{KOH}+\mathrm{Pt}_{\text {CAtalysts }} \rightarrow \mathrm{W}(\mathrm{OH})_{6}+3 \mathrm{H}_{2}+6 \mathrm{KOH}+\mathrm{Pt}_{\text {CATAlysts }}
$$

All presented STM images were recorded in constant current mode and processed by the WSXM image-processing software [50]. Before starting experimental investigations of the $\operatorname{Pt}(111)$ and $\mathrm{Au}-\mathrm{Pt}(111)$ surfaces, the experimental system was calibrated with the use of well know $\operatorname{Si}(111)-(7 \times 7)$ reconstructed surface [51-54] (Figure 1). $\operatorname{Si}(111)-(7 \times 7)$ surface was prepared by twice direct current flashing $(\mathrm{I}=4.0 \mathrm{~A})$ an $p$-type $\operatorname{Si}(111)$ substrate (size: $1 \times 10 \times 0.5 \mathrm{~mm}$, resistivity $\rho \approx 1-10 \Omega \mathrm{cm}$ ) at $1220 \mathrm{~K}$, after degassing at $970 \mathrm{~K}$ for two hours by joule heating with a current of $1 \mathrm{~A}$. Atomically 
resolved STM images of the empty and filed states of $\operatorname{Si}(111)-(7 \times 7)$ are presented in Figure 1 b,c, respectively. The measured surface unit cell is characterized by two diagonals of the diamond $\left(\mathrm{a}_{1}=46.6 \AA\right.$ and $\left.\mathrm{a}_{2}=26.9 \AA\right)$. Silicon adatoms (12 per unit cell) are marked in red in Figure $1 \mathrm{~b}$, and they occur as bright "dots" in empty-state STM image. Visible in STM images deep holes (depth $2 \AA$ ) are called corner hols.

(a)

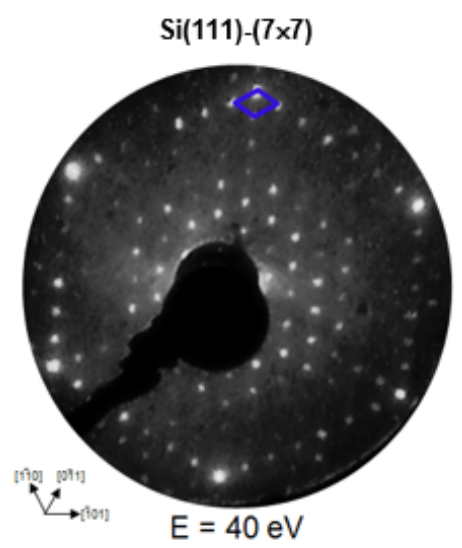

(d)

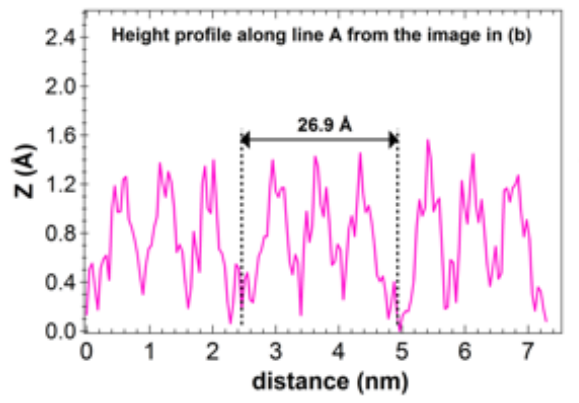

(b)

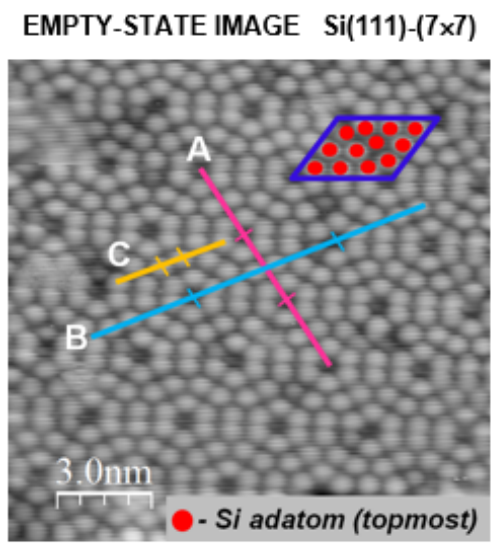

(e)

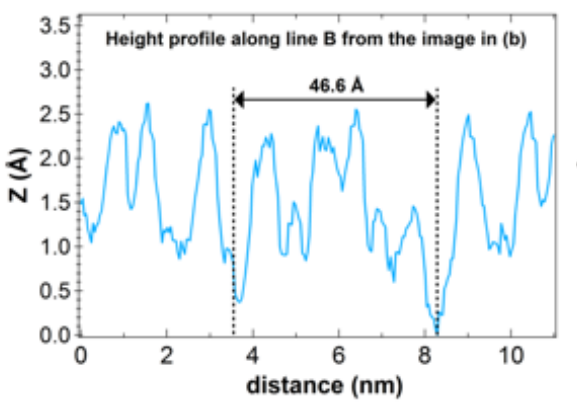

(c)

FILLED-STATE IMAGE Si(111)-(7×7)

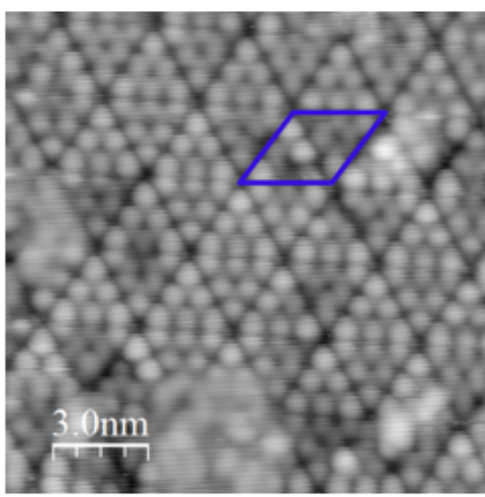

(f)

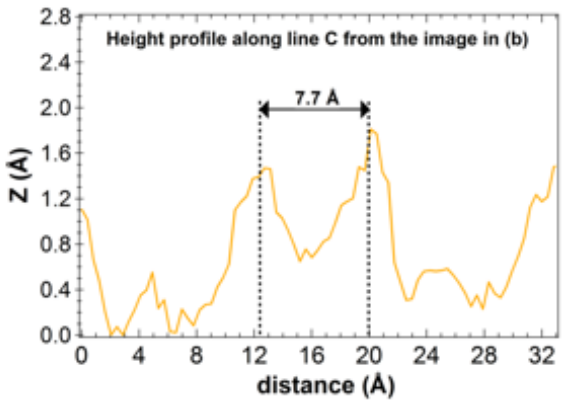

Figure 1. $\operatorname{Si}(111)-(7 \times 7)$ surface at $\mathrm{T}=300 \mathrm{~K}$ : $($ a) LEED patterns recorded at normal electron incidence for $\mathrm{E}=40 \mathrm{eV}$; (b) STM image of empty states $(150 \AA \times 150 \AA$, $\mathrm{I}_{\mathrm{T}}=0.5 \mathrm{nA}$, Ubias $\left.=+1.6 \mathrm{~V}\right)$; and (c) STM image of filled states $\left(150 \AA \times 150 \AA, \mathrm{IT}_{\mathrm{T}}=0.5 \mathrm{nA}\right.$, $\left.U_{\text {bias }}=-1.6 \mathrm{~V}\right)$. Au deposited on $\operatorname{Pt}(111)$ at $\mathrm{T}=300 \mathrm{~K}$ at a coverage $\theta_{\mathrm{Au}} \leq 1.0 \mathrm{ML}$ : (a) $\theta_{\mathrm{Au}} \approx 0.8 \mathrm{ML}\left(5000 \AA \times 5000 \AA, \mathrm{IT}_{\mathrm{T}}=4.0 \mathrm{nA}, \mathrm{U}_{\text {bias }}=1.0 \mathrm{~V}\right) ;(\mathbf{d}-\mathbf{f})$ line scans along the lines $\mathrm{A}, \mathrm{B}$, and $\mathrm{C}$ from the image in (b). The unit cell is indicated by the blue diamond (diagonals: $\mathrm{a}_{1}=46.6 \AA, \mathrm{a}_{2}=26.9 \AA$ ). Si adatoms (12 per surface unit cell) cell are marked as red dots.

\section{Calculation Details}

All calculations were performed based on the pseudo-potential plane-wave within the density functional theory [55,56], using the Cambridge serial total energy package (CASTEP) [57]. The effects of exchange correlation interaction are treated with the generalized gradient approximation (GGA) of Perdew-Burke-Ernzerhof (PBE) [58,59]. The ultra-soft pseudo-potentials [60] describe this electron-ion interaction system to high accuracy with a plane wave energy cutoff of $600 \mathrm{eV}$. The energy calculations in the first irreducible Brillouin-zone were conducted by using the $(4 \times 4 \times 1)$ k-point grid of the 
Monkhorst-Pack scheme [61]. Spin polarization of platinum was included in the calculations to correctly account for its magnetic properties. All atomic positions have been relaxed according to the total energy and force using the BFGS scheme [62] based on the cell optimization criterion RMS force of $0.03 \mathrm{eV} / \AA$, stress of $0.05 \mathrm{GPa}$, and displacement of $0.001 \AA$. The calculation of total energy and electronic structure is followed by cell optimization with SCF tolerance of $1 \times 10^{-6} \mathrm{eV} /$ atom. The $\mathrm{Pt}(111)$ surface was modeled using a slab containing $7(=15.84 \AA)$ and $10(=22.63 \AA)$ layers of Pt atoms with a vacuum gap in the [111] direction equal to $20.57 \AA$ and $30.37 \AA$, respectively. Full slab relaxation was performed in both cases.

\section{Results and Discussion}

\subsection{LEED and STM}

Gold atoms on the $\operatorname{Pt}(111)$ face form an ordered structure after evaporation onto the crystal face. Typical LEED pattern observed before and after deposition of gold on the $\operatorname{Pt}(111)$ face in normal electron incidence are shown in Figure 2. In this figure, the unit cell of the platinum lattice is indicated. The lattice constant of the platinum surface unit cell is $2.775 \AA$ (primitive $f c c$ (111) unit cell) [63]. The patterns are shown to demonstrate the quality of the structural order at the surface. It should be pointed out that the positions of the LEED spots associated with the $\mathrm{Pt}(111)$ substrate remains unchanged during the gold deposition at $300 \mathrm{~K}$ (Figure 2c), as was previously reported by Sachtler and Samorjai [32] and Vogt et al. [40]. Thus, the lattice constant of the first substrate layer remains constant, too, and suggests a two-dimensional growth of the first gold layer.

(a)

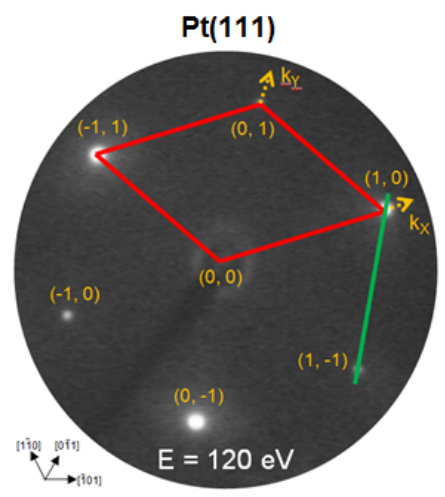

(b)

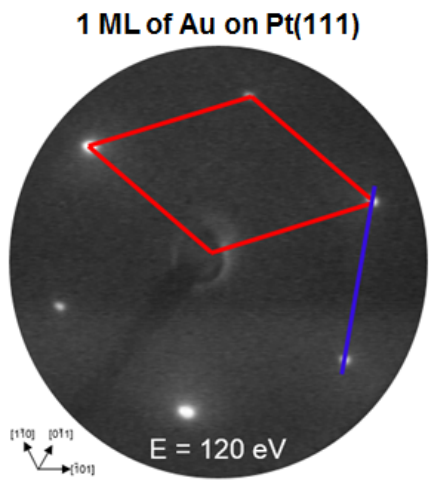

(c)

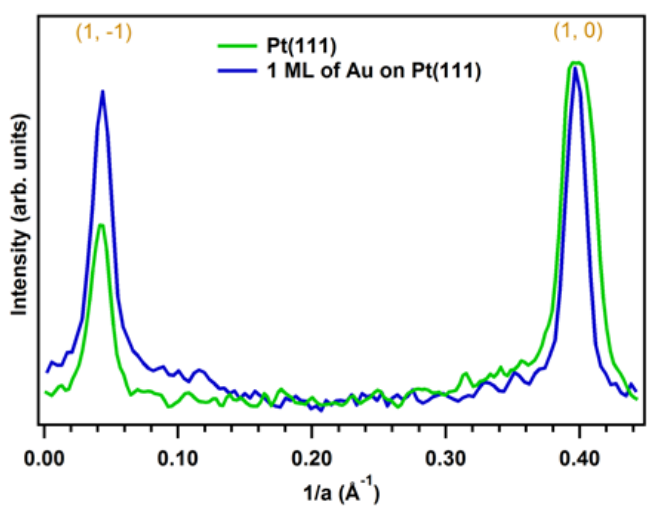

Figure 2. LEED patterns observed during the growth of $\mathrm{Au}$ on the $\operatorname{Pt}(111)$ surface recorded at normal electron incidence for $\mathrm{E}=120 \mathrm{eV}$, and $\mathrm{T}=300 \mathrm{~K}$ : (a) clean $\operatorname{Pt}(111)$ for $\mathrm{E}=120 \mathrm{eV} . k_{X}$ and $k_{Y}$ denote axes in the reciprocal lattice; (b) $1 \mathrm{ML}$ of Au on $\mathrm{Pt}(111)$; and (c) line profile along the lines from the image in $(\mathbf{a}, \mathbf{b})$ demonstrating that the position of LEED spots remain unchanged after gold deposition. The unit cell is outlined. 
(a)

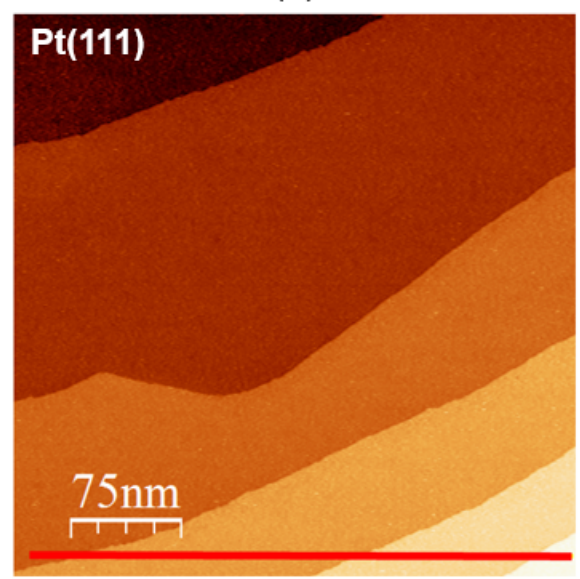

(b)

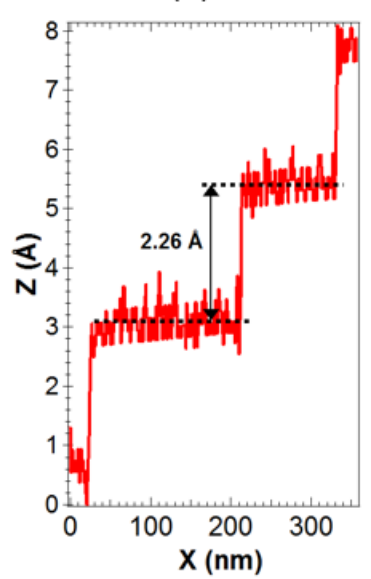

(c)

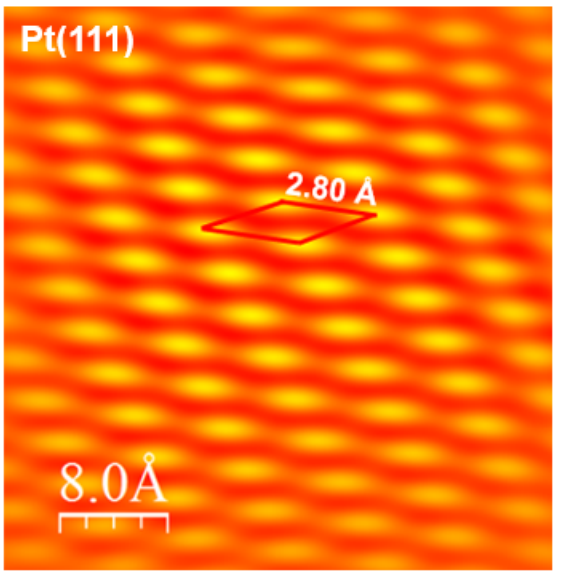

Figure 3. STM images of the clean Pt(111) surface: (a) $\mathrm{T}=25 \mathrm{~K}(3734 \AA \times 3734 \AA$, $\mathrm{IT}_{\mathrm{T}}=141 \mathrm{pA}$, Ubias $\left.=+50 \mathrm{mV}\right)$; (b) line-scan corresponding to line drawn in (a); and (c) $\mathrm{T}=300 \mathrm{~K}\left(40 \AA \times 40 \AA, \mathrm{IT}_{\mathrm{T}}=49 \mathrm{pA}, \mathrm{Ubias}=+48 \mathrm{mV}\right)$. The unit cell is outlined. STM image evidences a hexagonal lattice arrangement of $\mathrm{Pt}$ atoms with measured nearest neighbor distance of $2.80 \AA$.

The results of our STM measurements on the clean Pt(111) surface are presented in Figure 3. Figure 3a displays an STM image, taken on a low-index $\operatorname{Pt}(111)$ substrate with terraces between 100 and $300 \mathrm{~nm}$ width separated by monoatomic steps. The height of the steps on the $\operatorname{Pt}(111)$ surface was measured by STM to be $2.26 \pm 0.3 \AA$ (Figure $3 \mathrm{~b}$ ). However, one need to remember that the observed by STM step height includes geometric and electronic factors. Figure 3c presents atomic resolution of the $\operatorname{Pt}(111)$ face. The obtained topography shows a hexagonal lattice arrangement of Pt atoms with the nearest neighbor distance of $2.80 \AA$. This value describes the dimension of the surface unit cell and is $0.90 \%$ higher compared to the literature value $(=2.775 \AA)$ [63]. Figure $3 \mathrm{c}$ demonstrates that the surface structure seen in the obtained STM image has a clear long-range character. Figure 4 shows STM images of the $\mathrm{Pt}(111)$ surface with varying Au coverage in order to illustrate the morphology of the Au layers deposited on $\mathrm{Pt}$ at room temperature. Figure $4 \mathrm{a}$ shows a typical STM image corresponding to a submonolayer coverage of $\theta_{\mathrm{Au}} \approx 0.8 \mathrm{ML}$. An analysis of the STM measurements indicates that for coverage less than $1 \mathrm{ML}$, two-dimensional growth of gold layer is observed. This is in agreement with photoelectron spectroscopy study [38], our present and previous AES/LEED measurements [32,39]. The darker features in Figure 4a represent still visible platinum substrate as predicted in the previous studies [32]. Similar to the results observed by us, two-dimensional gold monolayer was obtained by electrodeposition of $\mathrm{Au}$ on $\mathrm{Pt}(111)$ from electrolytes containing $\mu \mathrm{M}$ concentrations of of $\mathrm{AuCl}_{4}^{-}$[42]. The line scan in Figure $4 \mathrm{~b}$ shows that the height of the first gold layer corresponds to the height of a single Pt step height equal to $2.26 \AA$. As the Au coverage is close to $1 \mathrm{ML}$, Au wets the Pt(111) surface completely, as can be seen in Figure 4c. This is not easy to confirm with STM, whether the surface is wetted or not. However, the reason for the perfect wetting is because of the high-specific surface free energy of the $\operatorname{Pt}(111)$ surface $\left(2.299 \mathrm{~J} / \mathrm{m}^{2}<\gamma_{\mathrm{Pt}}(111)<2.489 \mathrm{~J} / \mathrm{m}^{2}\right)$ [64-68] as compared with that of the $\mathrm{Au}(111)$ surface $\left(1.283 \mathrm{~J} / \mathrm{m}^{2}<\gamma_{\mathrm{Au}(111)}<1.506 \mathrm{~J} / \mathrm{m}^{2}\right)$ [64-68]. Since the total specific surface free energy should be minimized, a covered $\mathrm{Pt}(111)$ surface is favored [69]. Closer view of the STM image topography in Figure $4 \mathrm{~d}$ reveals the presence of well-ordered gold structures. STM images indicate a 
long-range order in the surface system. The obtained topography shows a hexagonal lattice arrangement of $\mathrm{Au}$ atoms with a nearest neighbor distance of $2.80 \AA$, which is exactly the same value as mentioned above in the case of Pt atoms. The same value of the surface unit cell after adsorption of gold could suggest that the gold atoms are adsorbed in sites (hollow $f c c$ or $h c p$ ), which are a direct continuation of the Pt lattice $A B C A B C A$. This is in good agreement with the supposition from the spin-resolved photoemission studies of Au-Pt(111) system [40], where the best fit of experimental results and theoretical model was achieved on that basis.

(a)

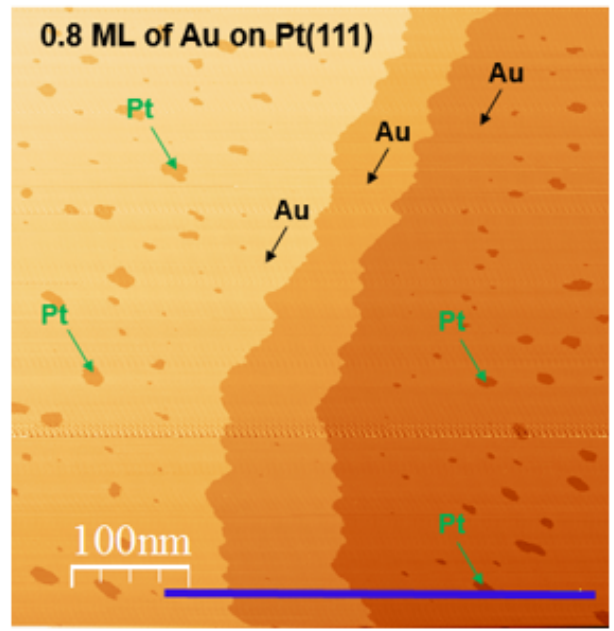

(c)

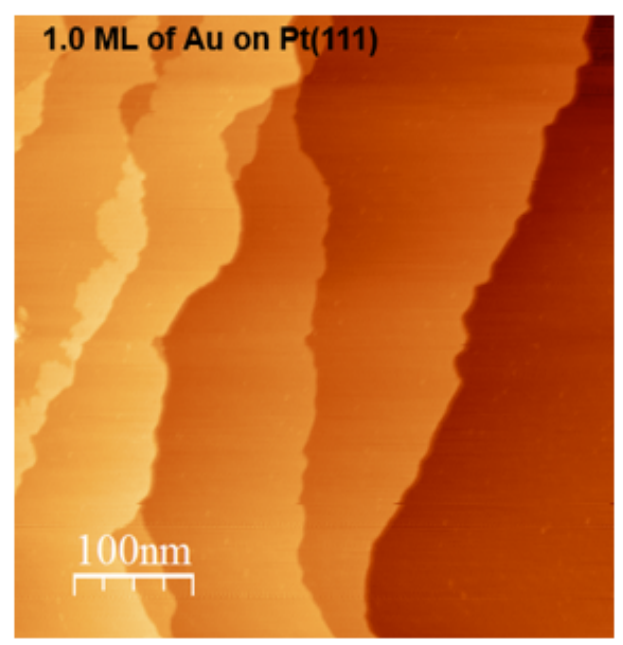

(b)

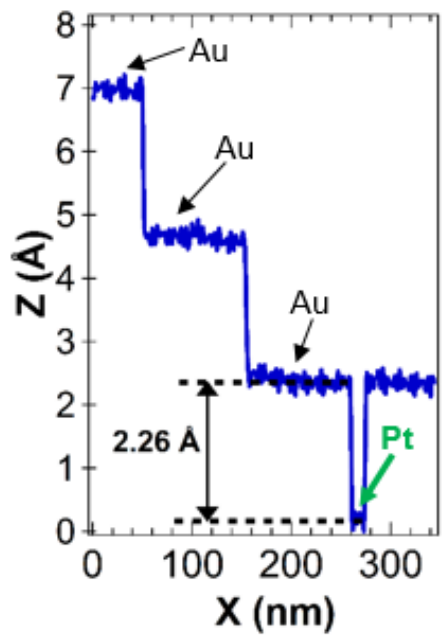

(d)

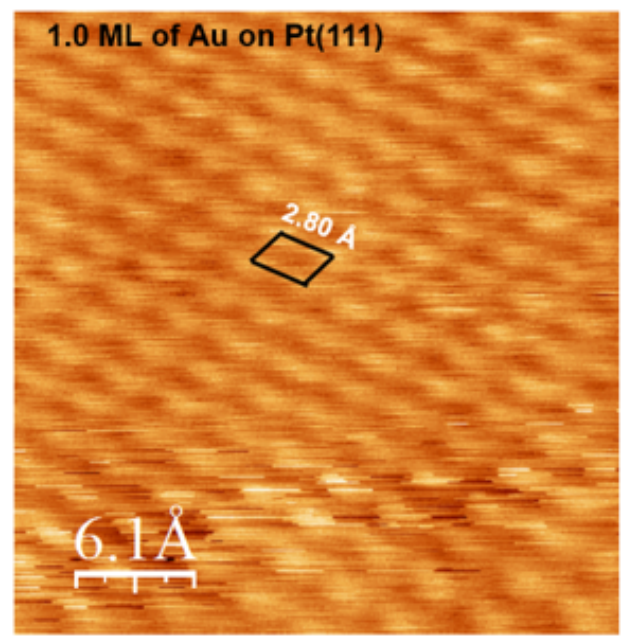

Figure 4. $\mathrm{STM}$ images of $\mathrm{Au}$ deposited on $\mathrm{Pt}(111)$ at $\mathrm{T}=300 \mathrm{~K}$ at a coverage $\theta_{\mathrm{Au}} \leq 1.0 \mathrm{ML}$ : (a) $\theta_{\mathrm{Au}} \approx 0.8 \mathrm{ML}\left(5000 \AA \times 5000 \AA, \mathrm{I}_{\mathrm{T}}=4.0 \mathrm{nA}, \mathrm{U}_{\text {bias }}=+1.0 \mathrm{~V}\right)$; (b) line scan along the line from the image in (a) demonstrating that the height of the gold layer corresponds to the height of a single Pt step height; (c) $\theta_{\mathrm{Au}} \approx 1.0 \mathrm{ML}(5000 \AA \times 5000 \AA$, IT $=2.0 \mathrm{nA}$, $\left.\mathrm{U}_{\text {bias }}=+1.0 \mathrm{~V}\right)$; and (d) $\left(30 \AA \times 30 \AA, \mathrm{I}_{\mathrm{T}}=4.65 \mathrm{nA}, \mathrm{U}_{\text {bias }}=+159 \mathrm{mV}\right)$. The unit cell is outlined. STM image evidences a hexagonal lattice arrangement of Au atoms with measured nearest neighbor distance of $2.80 \AA$. 


\subsection{DFT}

\subsubsection{Structure of Clean $\operatorname{Pt}(111)$}

In the theoretical part of our work, we have calculated multilayer relaxations of the $\operatorname{Pt}(111)$ system using the slab with 7 and 10 atomic layers. Figure 5a shows the schematic view of relaxed slab structure for the seven platinum layers. The platinum low-index surface was modeled by repeated slabs with a $(1 \times 1)$ surface unit cell with four atoms in each layer. The calculated atomic layer distances for seven and ten planes are shown in Table $1 . d_{i-j}^{X-Y}$ defines the distance along the surface normal direction between the $X$ atom at the $i$ atomic layer and the $Y$ atom at the $j$ atomic layer. Surface relaxation $\Delta d_{i-j}^{X-Y}$ is characterized as the percent of change of the spacing between layers $i$ and $j$ versus the bulk layer spacing $\left(\mathrm{d}^{0}\right)$. Bulk value $\left(\mathrm{d}_{0}\right)$ is taken from our GGA calculations and describes average distance between atomic planes of seven $(=2.30 \AA)$ and ten $(=2.29 \AA)$ platinum layers, respectively. Further calculations of gold adsorption on $\mathrm{Pt}(111)$ surface has been performed on seven platinum layers.

(a)

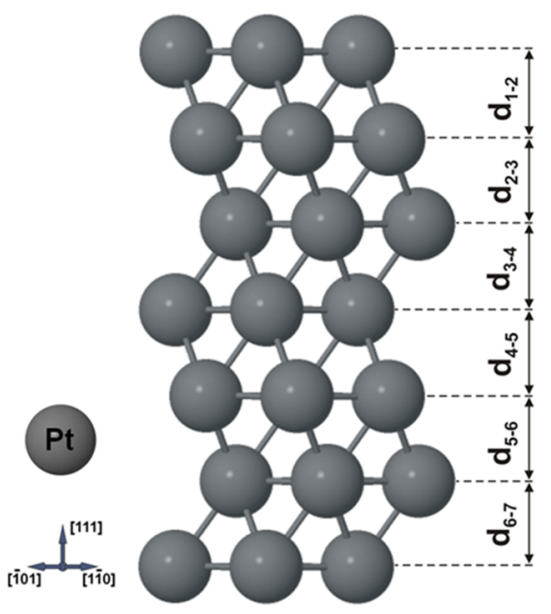

(b)

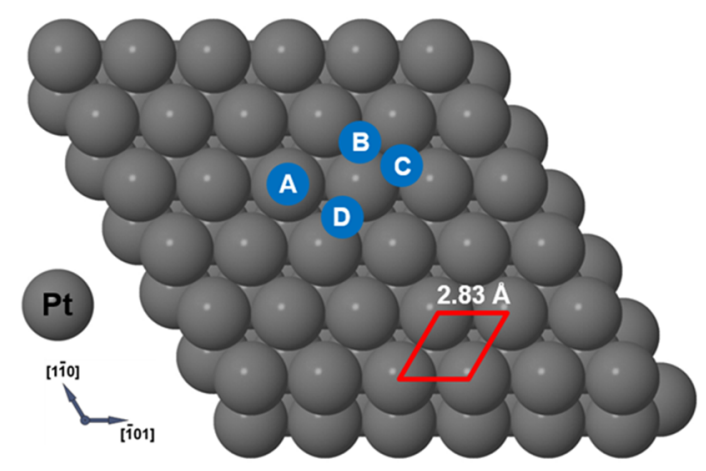

Figure 5. (a) Side view of the relaxed Pt(111) surface for seven layers. Values of denoted characteristic inter plane distances are given in Table 1. (b) Considered positions of $\mathrm{Au}$ adsorption on the $\operatorname{Pt}(111)$ surface: $\mathrm{A}$-on top; $\mathrm{B}$-hollow $f c c$; $\mathrm{C}$-hollow $h c p$; and $\mathrm{D}$-bridge. The unit cell is outlined. The nearest neighbor Pt-Pt distance of $2.83 \AA$ is obtained from our theoretical calculations.

Our calculations for the clean Pt(111) show very good agreement with the above-presented STM results and with the other experimental and theoretical literature studies [15,16,18,20-23,26,30,70,71] presented in Table 1. Obtained lateral geometrical properties of $\operatorname{Pt}(111)$ surface and distances between the nearest Pt atoms in the structure $(=2.83 \AA)$ are very close to STM measurements $(=2.80 \AA)$, with the difference about $1 \%$. The first and second interlayer spacings of the clean $\operatorname{Pt}(111)$ surface were determined to be $2.32 \AA$ and $2.29 \AA$, respectively, in case of calculated slab with seven atomic layers. This corresponds to a $+0.87 \%$ expansion and $-0.43 \%$ contraction of the first and second metal layer spacings of the ideally terminated $\operatorname{Pt}(111)$ clean surface $(=2.30 \AA)$, respectively. These values and the value obtained in our calculations of lattice constant of the bulk $\mathrm{Pt}(=3.99 \AA)$ are in excellent agreement with the previous GGA calculations [70] and surface X-ray diffraction results [26] (Table 1). However, 
comparison of our calculations to the quantitative low-energy electron diffraction value of the first interlayer spacing shows that our theoretical value $(=2.32 \AA)$ is slightly larger $(+2 \%)$ then the average value of $2.27 \AA$ observed experimentally [15,16,18,20-23].

Table 1. Distances $\left(d_{i-j}^{X-Y}\right)$ between the atomic planes of the relaxed $\operatorname{Pt}(111)$ system, and their percentage changes $\left(\Delta d_{i-j}^{X-Y}\right)$ with respect to the bulk value $\left(\mathrm{d}_{0}\right)$, calculated for the slab with 7 and 10 atomic layers and compared with experimental [15,16,18,20-23,26,72] and theoretical $[30,70,71]$ literature data. Notation of inter-plane distances are the same as in Figure $1 . d_{i-j}^{X-Y}$ denotes the interlayer spacing between layers $i$ and $j$ for the $X$ and $Y$ atoms type. $d_{0}$-average distance between atomic planes of seven and ten layers, respectively. a 0 - lattice constant of Pt. GGA — generalized gradient approximation, LDA-local density approximation, LEED — low energy electron diffraction, SXRD — surface X-ray diffraction.

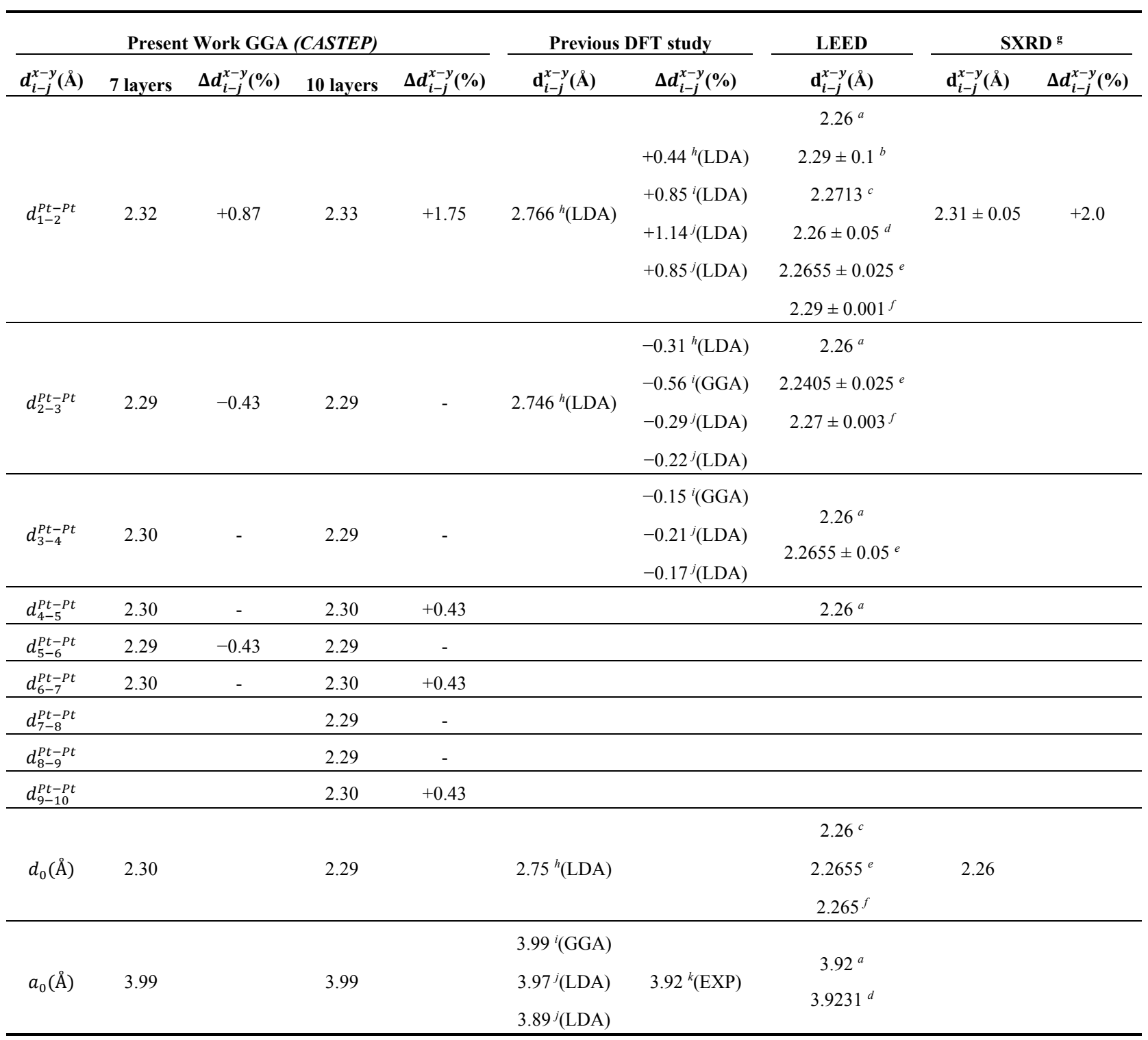

${ }^{a}$ Ref. [15,16]; ${ }^{b}$ Ref. [18]; ${ }^{c}$ Ref. [20]; ${ }^{d}$ Ref. [21]; ${ }^{e}$ Ref. [22]; ${ }^{f}$ Ref. [23]; ${ }^{g}$ Ref. [26]; ${ }^{h}$ Ref. [30]; ${ }^{i}$ Ref. [70]; ${ }^{j}$ Ref. [71]; ${ }^{k}$ Ref. [72]. 


\subsubsection{Structure of the $\mathrm{Au} / \mathrm{Pt}(111)$ System}

Figure $5 \mathrm{~b}$ shows the four possible gold adsorption sites on the $\operatorname{Pt}(111)$ surface with one on-top site (labeled as A), two hollow sites: hollow $f c c$ (labeled as B), hollow hcp (labeled as C), and one bridge site (labeled as D), In our calculations, we define one monolayer of adsorbed Au atoms corresponding to the same atoms as the atomic sites in the surface layer. One Au atom adsorbing on the Pt(111) surface corresponds to an adsorption coverage of $0.25 \mathrm{ML}$. The minimum adsorption energy (Eads) was calculated by means of the following total energy difference:

$$
E_{a d s}=E_{T}\left(\frac{A u}{\operatorname{Pt}(111)}\right)-E_{T}(A u)-E_{T}(\operatorname{Pt}(111))
$$

where $E_{T}$ is the total energy of the system and $\frac{A u}{\operatorname{Pt}(111)}, A u$, and $\operatorname{Pt}(111)$ refer to the atom-on-metal system, the free Au atom, and the bare Pt surface, respectively.

Table 2 displays the predicted adsorption energies of $\mathrm{Au}$ on the $\operatorname{Pt}(111)$ surface and the distance between the $\mathrm{Au}$ atom and its nearest $\left(r_{N N}\right)$ and next nearest neighbors $\left(r_{N N N}\right)$. A, B, C and D describe positions of $\mathrm{Au}$ atom on the $\mathrm{Pt}(111)$ surface before starting calculations. As one can see, only in the case of bridge position $\mathrm{D}$ displacement of gold atom towards hollow $f c c$ position $\mathrm{B}$ is observed, while the other gold adsorption positions described as $\mathrm{A}, \mathrm{B}$ and $\mathrm{C}$ remain unchanged. The comparison of the calculated adsorption energies reveals that the preferred position of the $\mathrm{Au}$ on the $\operatorname{Pt}(111)$ surface is the hollow $f c c$ with the $\mathrm{E}_{\mathrm{ads}}=-0.578 \mathrm{eV}$. At this favorable position, the nearest to the nearest $(\mathrm{NN})$ and next-nearest (NNN) neighbor distance is equal to $2.58 \AA$ and $3.76 \AA$, respectively. The adsorption energy of one gold atom in hollow $f c c$ site is negative, which indicates in addition that this adsorption position is the most stable. Similar conclusion was obtained in case of a quantitative LEED analysis of the structure of $\operatorname{Pt}(111)(\sqrt{3} \times \sqrt{3}) \mathrm{R} 30^{\circ}-\mathrm{S}$, where the best agreement between experiment and theory has been found for a model with a sulfur atom in the three-fold hollow $f c c$ site [21]. Moreover, our theoretical studies are in agreement with the spin-resolved photoemission predictions where the Au is adsorbed in sites, which are a direct continuation of the Pt lattice [40]. In contrast to very stable hollow $f c c$ site, the on-top adsorption position is the most unstable place with $\mathrm{E}_{\mathrm{ads}}=+0.580 \mathrm{eV}$. Next, taking into account our experimental STM results, we have considered structural model of the $\mathrm{Au} / \mathrm{Pt}(111)$ surface reproducing in the best way the topography of the obtained STM images. Structural relaxation has shown that such a model is stable. The lateral positions of all gold atoms in the relaxed structure remained the same as in the starting configuration. This model assumes that the gold structure is built up by Au hollow $f c c$ and hollow hcp atoms (Figure 6). The obtained lateral geometrical properties of this $\mathrm{Au} / \mathrm{Pt}(111)$ model and distances between the nearest gold atoms in the structure $(=2.83 \AA)$ are almost the same as those following STM measurements $(=2.80 \AA$ ) with the difference close to $1 \%$. Table 3 presents obtained changes in the $\mathrm{Pt}(111)$ geometry induced by presence of a two-dimensional gold layer. Namely, we find the top interlayer spacing $d^{P t-A u}$ noticeably expanded by $+2.16 \%$ with respect to the ideal platinum bulk value $\left(=2.31 \AA\right.$ ). The calculated value of the surface free energy of gold layer equals to $\gamma_{\mathrm{Au}}=1.481 \mathrm{~J} / \mathrm{m}^{2}$, and it is in very good agreement with the value of the surface free energy of $\mathrm{Au}(111)$ mentioned in literature $\left(1.283 \mathrm{~J} / \mathrm{m}^{2}<\gamma_{\operatorname{Au}(111)}<1.506 \mathrm{~J} / \mathrm{m}^{2}\right)[64-68]$. 
Table 2. Calculation results of one $\mathrm{Au}$ atom adsorption on the $\mathrm{Pt}(111)$ surface. Eads - adsorption energy; $r_{N N}$ and $r_{N N N}$ describe the distance to the nearest $(\mathrm{NN})$ and next-nearest $(\mathrm{NNN})$ neighbors. $\mathrm{D} \rightarrow \mathrm{B}$ means that after calculations gold atom has moved from the bridge position $\mathrm{D}$ towards the most favorable hollow $f c c$ position $\mathrm{B}$.

\begin{tabular}{ccccc}
\hline $\mathbf{( 1 1 1 )}$ & Site & $\boldsymbol{E}_{\text {ads }}(\mathbf{e V})$ & $\boldsymbol{r}_{N N}(\AA)$ & $\boldsymbol{r}_{N N N}(\AA)$ \\
\hline Au on top & $\mathrm{A}$ & +0.580 & 2.58 & 3.76 \\
Hollow $f c c$ & $\mathrm{~B}$ & -0.578 & 2.74 & 3.89 \\
Hollow $h c p$ & $\mathrm{C}$ & -0.518 & 2.75 & 3.92 \\
Bridge & $\mathrm{D} \rightarrow \mathrm{B}$ & -0.578 & 2.74 & 3.89 \\
\hline
\end{tabular}

Table 3. Calculated distances $\left(\boldsymbol{d}_{i-j}^{X-Y}\right)$ between the atomic planes of the relaxed Au-Pt(111) system, and their percentage changes $\left(\Delta d_{i-j}^{X-Y}\right)$ with respect to the ideal Pt bulk value $\left(\mathrm{d}_{0}\right)$, for the slab with eight atomic layers (see slab and top view of the considered structure in Figure 6).

\begin{tabular}{ccc}
\hline $\boldsymbol{d}_{\boldsymbol{i}-\boldsymbol{j}}^{\boldsymbol{X}-\boldsymbol{Y}}(\boldsymbol{\AA} \mathbf{\AA})$ & \multicolumn{2}{c}{$\begin{array}{c}\text { Adsorption Site B } \\
\mathbf{8} \text { Layers } \Delta \boldsymbol{d}_{\boldsymbol{i}-\boldsymbol{j}}^{\boldsymbol{X - \boldsymbol { Y }}} \mathbf{( \% )}\end{array}$} \\
\hline$d_{.}^{P t-A u}$ & 2.36 & +2.16 \\
$d_{1-2}^{P t-P t}$ & 2.34 & +1.30 \\
$d_{2-3}^{P t-P t}$ & 2.31 & - \\
$d_{3-4}^{P t-P t}$ & 2.32 & +0.43 \\
$d_{4-5}^{P t-P t}$ & 2.31 & - \\
$d_{5-6}^{P t-P t}$ & 2.30 & -0.43 \\
$d_{6-7}^{P t-P t}$ & 2.33 & +0.86 \\
$\mathrm{~d}_{0}$ & 2.31 & - \\
\hline
\end{tabular}

(a)

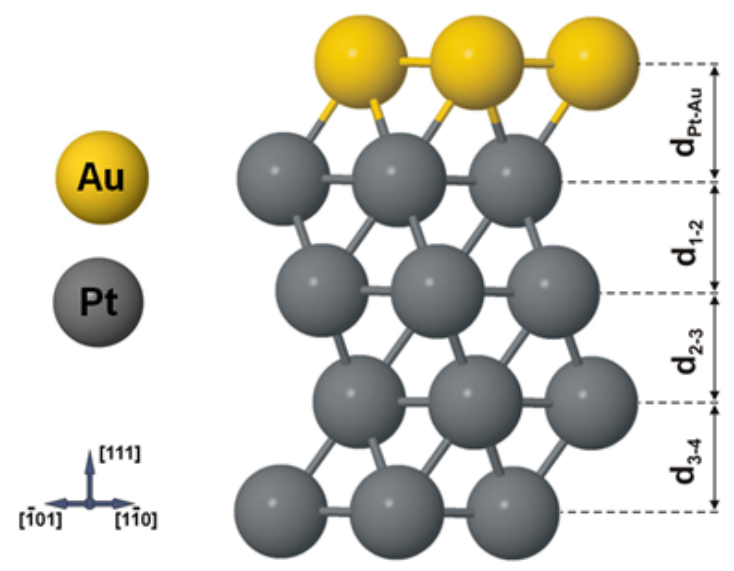

(b)

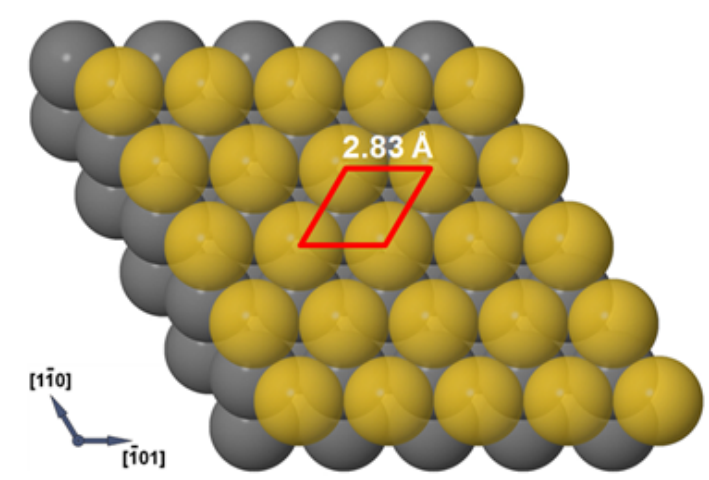

Figure 6. (a) Side view of the calculated most stable hollow $f c c$ position of a relaxed $\mathrm{Au}$ atom on the $\mathrm{Pt}(111)$ surface; (b) top view of the calculated $\mathrm{Au} / \mathrm{Pt}(111)$ surface. The unit cell is outlined. The nearest neighbor Au-Au distance of $2.83 \AA$ is obtained from our theoretical calculations. 


\subsubsection{Density of States}

The calculated electronic structure (density of states-DOS) for the studied adsorption system is presented in Figure 7. The DOS curve for bare $\mathrm{Pt}(111)$ and $\mathrm{Pt}(111)$ covered by Au is displayed in Figure $7 \mathrm{a}$ as red dotted and black line, respectively. In case of $\mathrm{Au} / \mathrm{Pt}(111)$ surface, the DOS curve was obtained by considering gold atoms sitting in the most stable hollow $f c c$ positions. Density of states distributions of $\operatorname{Pt}(111)$ and $\mathrm{Au} / \mathrm{Pt}(111)$ systems were calculated for seven (clean platinum) and eight (one gold monolayer on platinum) atomic layers, respectively. In the case of density of states for clean $\operatorname{Pt}(111)$ surface, our results are in very good agreement with previous theoretical studies [73-77]. Changes in the electronic properties of our $\mathrm{Au} / \mathrm{Pt}(111)$ system, compared to $\mathrm{Pt}(111)$, are visible. In particular, noticeable increase in the intensity of occupied states in the energy range between -5 and $-1 \mathrm{eV}$, and slight change of the DOS shape after including of one gold layer into calculations. Both alterations, mainly attributed to the interaction of $\mathrm{Au}$ atoms with $\mathrm{Pt}(111)$ surface $[39,40]$, are represented by the projection of the adsorbed gold density of states in Figure 7a. Density of states distribution calculated for the bulk platinum presented in Figure 7b, confirms well that the electronic structure of platinum is dominated by $\mathrm{d}$ state within the whole considered energy range.

(a)

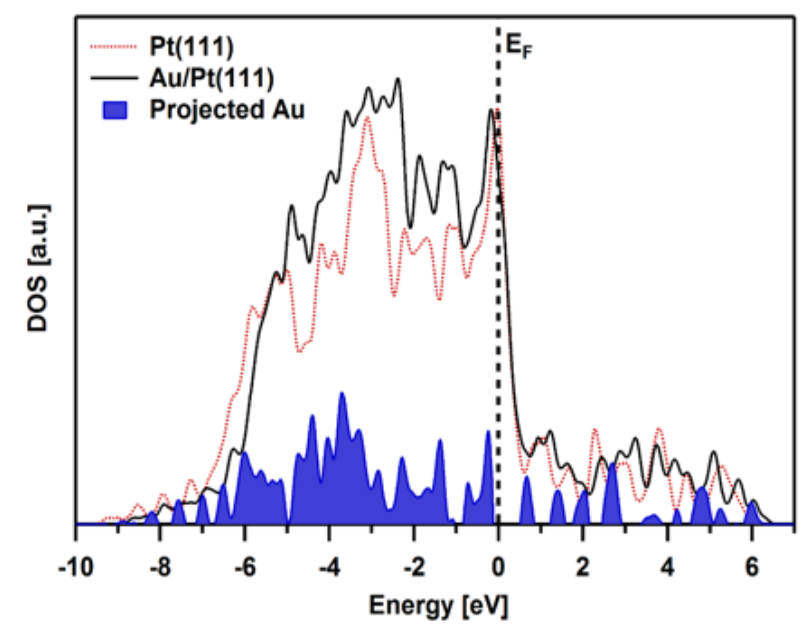

(b)

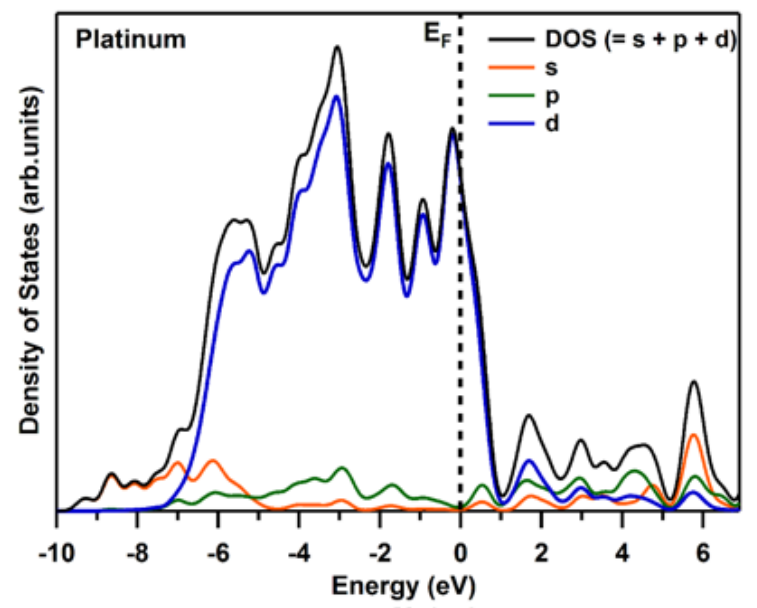

Figure 7. Density of states curves for gold on Pt(111): (a) Clean Pt(111) (red dotted line); $1 \mathrm{ML}$ of Au on $\mathrm{Pt}(111)$ (black line). The projection of the adsorbed gold density of states is shaded in blue. (b) Clean bulk platinum (black line) and its components associated with $\mathrm{s}$ (orange line), $\mathrm{p}$ (green line) and d (blue line) orbitals. EF denotes Fermi level.

\section{Conclusions}

In this work, experimental and theoretical studies of the geometrical and electronic properties of (111) surface of the ordered Au-Pt adsorption system have been presented. The analysis of LEED and STM measurements indicates that for a coverage below $1 \mathrm{ML}$, two-dimensional growth of the first $\mathrm{Au}$ monolayer takes place. Based on LEED results, no change of the lattice constant after gold adsorption was observed. The topography of the obtained STM images of $\operatorname{Pt}(111)$ and $\mathrm{Au} / \mathrm{Pt}(111)$ surfaces on the level of the atomic resolution demonstrate that the surface structures have hexagonal arrangement of 
atoms and that the surface lattice constant is equal to the distance between the nearest platinum surface atoms $(=2.80 \AA)$. This is in very good agreement (close to $1 \%$ ) with our presented DFT calculations, where the distances between the nearest atoms in the case of bare $\operatorname{Pt}(111)$ and $\mathrm{Au} / \mathrm{Pt}(111)$ surface equal to $2.83 \AA$. It was shown that the first and second interlayer spacings of the clean $\operatorname{Pt}(111)$ surface were determined to be expanded by $+0.87 \%$ and contracted by $-0.43 \%$, respectively. The calculated adsorption energy of the $\mathrm{Au}$ atom on the $\mathrm{Pt}(111)$ surface is dependent on the adsorption site, and there is a preference for a hollow $f c c$ site $\left(\mathrm{E}_{\mathrm{ads}}=-0.578 \mathrm{eV}\right)$. In the presence of gold layer on the $\operatorname{Pt}(111)$ surface, the top interlayer spacing was found expanded by $+2.16 \%$ with respect to the ideal bulk value. Density of states for the $\operatorname{Pt}(111)$ surface present very good agreement with previous literature studies, while observed changes in the electronic properties of the $\mathrm{Au} / \mathrm{Pt}(111)$ system below the Fermi level are mainly connected to the interaction of $\mathrm{Au}$ atoms with $\mathrm{Pt}(111)$ surface.

\section{Acknowledgments}

Katarzyna Krupski acknowledges funding from the University of Warwick Chancellor's scholarship. Work of Paweł Jóźwik and his research stay at the University of Warwick (IX 2014) was supported by the Military University of Technology in Warsaw under Grant No. 853/2013/MUT. Work of Tomasz Kobiela and his research stay at the University of Warwick (VII 2014) was supported by the Warsaw University of Technology. Katarzyna and Aleksander Krupski would like to thank Beata and Marek Chirek for useful discussions. Theoretical part of research was partly supported by PL-Grid Infrastructure [78].

\section{Author Contributions}

Aleksander and Katarzyna Krupski developed the concept and designed the manuscript. Marco Moors, Tomasz Kobiela, Paweł Jóźwik, Katarzyna and Aleksander Krupski have done STM measurements. Katarzyna Krupski has done DFT calculations. Katarzyna and Aleksander Krupski prepared the manuscript. Aleksander Krupski edited the English language. Katarzyna Krupski, Marco Moors, Tomasz Kobiela, Paweł Jóźwik, and Aleksander Krupski discussed the manuscript at all stages.

\section{Conflicts of Interest}

The authors declare no conflict of interest.

\section{References}

1. Himpsel, F.; Ortega, J.; Mankey, G. Magnetic nanostructures. Adv. Phys. 1998, 47, 511-597.

2. Larsen, J.; Chorkendorff, I. From fundamental studies of reactivity on single crystals to the design of catalysts. Surf. Sci. Rep. 1999, 35, 163-222.

3. Krupski, A. Growth morphology of thin films on metallic and oxide surfaces. J. Phys. Condens. Matter 2014, 26, 053001-053026.

4. Jiang, M.; Sak, E.; Gentz, K.; Krupski, A.; Wandelt, K. Redox activity and structural transition of heptyl viologen adlayers on $\mathrm{Cu}(100)$. ChemPhysChem 2010, 11, 1542-1549. 
5. Krupski, A.; Mróz, S. Properties of ultrathin Sb layers on the Ni(111) face. Surf. Rev. Lett. 2003, $10,65-72$.

6. Mróz, S.; Nowicki, M.; Krupski, A. Directional elastic peak electron spectroscopy: Theoretical description and review of applications. Prog. Surf. Sci. 2003, 74, 109-122.

7. Krupski, A.; Mróz, S. Leed investigation of the $\mathrm{Pb}$ and $\mathrm{Sb}$ ultrathin layers deposited on the Ni(111) face at $\mathrm{T}=150-900 \mathrm{~K}$. Surf. Rev. Lett. 2003, 10, 843-848.

8. Jurczyszyn, L.; Krupski, A.; Degen, S.; Pieczyrak, B.; Kralj, M.; Becker, C.; Wandelt, K. Atomic structure and electronic properties of $\mathrm{Ni}_{3} \mathrm{Al}(111)$ and (011) surfaces. Phys. Rev. B 2007, 76, 045101, doi:10.1103/PhysRevB.76.045101.

9. Krupski, A. Pb on Mo(110) studied by scanning tunneling microscopy. Phys. Rev. B 2009, 80, 035424, doi:10.1103/PhysRevB.80.035424.

10. Miśków, K.; Krupski, A.; Wandelt, K. Growth morphology of $\mathrm{Pb}$ films on $\mathrm{Ni} 3 \mathrm{Al}(111)$. Vacuum 2014, 101, 71-78.

11. Thomas, J.M.; Thomas, W.J. Principles and Practice of Heterogeneous Catalysis; VCH: New York, NY, USA, 1997.

12. Somorjai, G.A. Introduction to Surface Chemistry and Catalysis; Wiley: New York, NY, USA, 1994.

13. Masel, R.I. Principles of Adsorption and Reaction on Solid Surfaces; Wiley: New York, NY, USA, 1996.

14. Speight, J.G. The Chemistry and Technology of Petroleum, 2nd ed.; Marcel-Dekker: New York, NY, USA, 1991.

15. Kesmodel, L.L.; Samorjai, G.A. Structure determination of the platinum (111) crystal face by low-energy-electron diffraction. Phys. Rev. B 1975, 11, 630-637.

16. Kesmodel, L.L.; Stair, P.C.; Somorjai, G.A. On the relaxation of the Pt(111) surface: Results of dynamical LEED calculations. Surf. Sci. 1975, 64, 342-344.

17. Feder, R. Spin-polarized LEED from low-index surfaces of platinum and gold. Surf. Sci. 1977, 68, 229-235.

18. Adams, D.L.; Nielsen, H.B.; van Hove, M.A. Quantitative analysis of low-energy-electron diffraction: Application to Pt(111). Phys. Rev. B 1979, 20, 4789-4806.

19. Bauer, P.; Feder, R.; Mueller, N. Spin polarization in low-energy electron diffraction from Pt(111): Experiment and theory. Surf. Sci. 1980, 99, L395-L401.

20. Feder, R.; Pleyer, H.; Bauer, P.; Mueller, N. Spin polarization in low-energy electron diffraction: Surface analysis of Pt(111). Surf. Sci. 1981, 109, 419-434.

21. Hayek, K.; Glassl, H.; Gutmann, A.; Leohard, H. A LEED analysis of the structure of $\operatorname{Pt}(111)(\sqrt{3} \times \sqrt{3}) \mathrm{R} 30^{\circ}-$ S. Surf. Sci. 1985, 152-153, 419-425.

22. Ogletree, D.F.; van Hove, M.A.; Samorjai, G.A. LEED intensity analysis of the structures of clean $\mathrm{Pt}(111)$ and of $\mathrm{CO}$ adsorbed on $\mathrm{Pt}(111)$ in the c $(4 \times 2)$ arrangement. Surf. Sci. 1986, 173, 351-365.

23. Materer, N.; Starke, U.; Barbieri, A.; Doell, R.; Heinz, K.; van Hove, M.A.; Samorjai, G.A. Reliability of detailed LEED structural analyses: $\operatorname{Pt}(111)$ and $\operatorname{Pt}(111)-\mathrm{p}(2 \times 2)-O$. Surf. Sci. 1995, $325,207-222$. 
24. Davies, J.A.; Jackson, D.P.; Matsunami, N.; Norton, P.R. Temperature dependence of Pt(111) surface relaxation. Surf. Sci. 1978, 78, 274-294.

25. Van der Veen, J.F.; Smeenk, R.G.; Tromp, R.M.; Saris, F.W. Relaxation effects and thermal vibrations in a $\operatorname{Pt}(111)$ surface measured by medium energy ion scattering. Surf. Sci. 1979, 79, 219-230.

26. Felici, R.; Pedio, M.; Borgatti, F.; Iannotta, S.; Capozi, M.; Ciullo, G.; Stierle, A. X-ray-diffraction characterization of $\operatorname{Pt}(111)$ surface nanopattering induced by $\mathrm{C} 60$ adsorption. Nat. Mater. 2005, 4, 688-692.

27. Krupski, A.; Krupski, K.; Bailly, A.; Saint-Lager, M.C.; Baudoing-Savois, R.; Dolle, P.; Becker, C.; Wandelt, K. Structure determination of the $\operatorname{Pt}(111)(2 \times 2)-\operatorname{Sn}$ and $\operatorname{Pt}(111)(\sqrt{ } 3 \times \sqrt{3}) \mathrm{R} 30^{\circ}-\mathrm{Sn}$ surface alloys: Surface X-ray-Diffraction and DFT study. In preparation.

28. Grübel, G.; Huang, K.G.; Gibbs, D.; Zehner, D.M.; Sandy, R.S.; Mochrie, S.G.J. Reconstruction of the Pt(111) surface: X-ray-scattering measurements. Phys. Rev. B 1993, 48, 18119-18139.

29. Sandy, A.R.; Mochrie, S.G.J.; Zehner, D.M.; Huang, K.G.; Gibbs, D. Structure and phases of the $\mathrm{Au}(111)$ surface: X-ray-scattering measurements. Phys. Rev. B 1991, 43, 4667-4687.

30. Feibelman, P.J. First-principles calculations of stress induced by gas adsorption on Pt(111). Phys. Rev. B 1997, 56, 2175-2182.

31. Davies, P.W.; Quinlan, M.A.; Samorjai, G.A. The growth and chemisorptive properties of Ag and Au monolayers on platinum single crystal surfaces: An AES, TDS and LEED study. Surf. Sci. 1982, 121, 290-302.

32. Sachtler, J.W.A.; Somorjai, G.A. Influence of ensemble size on CO chemisorption and catalytic $n$-hexane conversion by Au-Pt(111) bimetallic single-crystal surfaces. J. Catal. 1983, 81, 77-94.

33. Sachtler, J.W.A.; Somorjai, G.A. Cyclohexane dehydrogenation catalyzed by bimetallic Au-Pt(111) single-crystal surfaces. J. Catal. 1984, 89, 35-43.

34. Yeates, R.C.; Somorjai, G.A. Surface structure sensitivity of alloy catalysis: Catalytic conversion of $n$-hexane over Au-Pt(111) and Au-Pt(100) alloy crystal surfaces. J. Catal. 1987, 103, 208-212.

35. Meyer, R.; Lemire, C.; Shaikhutdinov, S.K.; Freund, H.J. Surface chemistry of catalysis by gold. Gold Bull. 2004, 37, 72-124.

36. Kobiela, T.; Kaszkur, Z.; Duś, R. Fabrication of Au nanostructures in the process of amalgam formation followed by Au-Hg alloy thermal decomposition. Thin Solid Films 2005, 78, 152-158.

37. Kobiela, T.; Moors, M.; Linhart, W.; Cebula, I.; Krupski, A.; Becker, C.; Wandelt, K. Characterization of bimetallic Au-Pt(111) surfaces. Thin Solid Films 2010, 518, 3650-3657.

38. Salmeron, M.; Ferrer, S.; Jazzar, M.; Samorjai, G.A. Photoelectron-spectroscopy study of the electronic structure of Au and Ag overlayers on $\operatorname{Pt}(100), \operatorname{Pt}(111)$, and $\operatorname{Pt}(997)$ surfaces. Phys. Rev. B 1983, 28, 6758-6765.

39. Vogt, B.; Schmiedeskamp, B.; Heinzmann, U. Spin-resolved photoemission from epitaxial Au layers on $\mathrm{Pt}(111)$ : Coverage dependence of the bandstructure and evidence of surface resonances. Z. Phys. B Condens. Matter 1990, 80, 359-364.

40. Stoppmanns, P.; Heidemann, B.; Irmer, N.; Mueller, N.; Vogt, B.; Schmiedeskamp, B.; Heinzmann, U.; Tamura, E.; Feder, R. Au-Induced Surface State on $\operatorname{Pt}(111)$ Revealed by Spin-Resolved Photoemission with Linearly Polarized Light. Phys. Rev. Lett. 1991, 66, 2645-2648. 
41. Sibert, E.; Ozanam, F.; Maroun, F.; Magnussen, O.M.; Behm, R.J. Potential-Induced Strain Relaxation in Au Mono- and Bilayer Films on Pt(111) Electrode Surfaces. Phys. Rev. Lett. 2003, 90, 0561021-0561024.

42. Sibert, E.; Ozanam, F.; Maroun, F.; Behm, R.J.; Magnussen, O.M. Diffusion-limited electrodeposition of ultrathin Au films on Pt(111). Surf. Sci. 2004, 572, 115-125.

43. Potter, H.C.; Blakely, J.M. LEED, Auger spectroscopy, and contact potential studies of copper-gold alloy single crystal surfaces. J. Vac. Sci. Technol. 1975, 12, 635-642.

44. Hulse, J.; Kueppers, J.; Wandelt, K.; Ertl, G. UV-Photoelectron spectroscopy from xenon adsorbed on heterogeneous metal surfaces. Appl. Surf. Sci. 1980, 6, 453-463.

45. MaTeck. Available online: http://www.mateck.com/ (accessed on 27 April 2015).

46. Foiles, S.M.; Baskes, M.I.; Daw, M.S. Embedded-atom-method functions for the $f c c$ metals Cu, Ag, Au, Ni, Pd, Pt, and their alloys. Phys. Rev. B 1986, 33, 7983-7991.

47. Friatec. Available online: http://www.friatec.de/ (accessed on 27 April 2015).

48. Goodfellow. Available online: http://www.goodfellow.com/ (accessed on 27 January 2015).

49. SigmaAldrich. Available online: http://www.sigmaaldrich.com (accessed on 27 January 2015).

50. Horcas, I.; Fernández, R.; Gómez-Rodríguez, J.M.; Colchero, J.; Gómez-Herrero, J.; Baro, A.M. WSXM: A software for scanning probe microscopy and a tool for nanotechnology. Rev. Sci. Instrum. 2007, 78, 013705, doi:10.1063/1.2432410.

51. Avouris, Ph.; Wolkow, R. Atom-resolved surface chemistry studied by scanning tunneling microscopy and spectroscopy. Phys. Rev. B 1989, 39, 5091-5100.

52. Piancastelli, M.N.; Motta, N.; Sgarlata, A.; Balzarotti, A.; de Crescenzi, M. Topographic and spectroscopic analysis of ethylene adsorption on $\mathrm{Si}(111)-(7 \times 7)$ by STM and STS. Phys. Rev. $B$ 1993, 48, 17892-17896.

53. Giessibl, F.J. Atomic Resolution of the Silicon(111)- $(7 \times 7)$ Surface by Atomic Force Microscopy. Science 1995, 267, 68-71.

54. Neddermeyer, H. Scanning tunnelling microscopy of semiconductor surfaces. Rep. Prog. Phys. 1996, 59, 701-769.

55. Kohn, W.; Sham, L.J. Self-Consistent Equations Including Exchange and Correlation Effects. Phys. Rev. A 1965, 140, 1133, doi:10.1103/PhysRev.140.A1133.

56. Hohenberg, P.; Kohn, W. Inhomogeneous Electron Gas. Phys. Rev. B 1964, 136, doi:10.1103/ PhysRev.136.B864.

57. Segall, M.D.; Lindan, P.J.D.; Probert, M.J.; Pichard, C.J.; Hasnip, P.J.; Clark, S.J.; Payne, M.C. First-principles simulation: Ideas, illustrations and the CASTEP code. J. Phys. Condens. Matter 2002, 14, 2717-2744.

58. Perdew, J.P.; Chevary, J.A.; Vosko, S.H.; Jackson, K.A.; Pederson, M.R.; Singh, D.J.; Fiolhais, C. Atoms, molecules, solids, and surfaces: Applications of the generalized gradient approximation for exchange and correlation. Phys. Rev. B 1992, 46, 6671-6687.

59. Perdew, J.P.; Burke, K.; Ernzerhof, M. Generalized Gradient Approximation Made Simple. Phys. Rev. Lett. 1996, 77, 3865-3868.

60. Vanderbilt, D. Soft self-consistent pseudopotentials in a generalized eigenvalue formalism. Phys. Rev. B 1990, 41, 7892-7895. 
61. Monkhorst, H.J.; Pack, J.D. Special points for Brillouin-zone integrations. Phys. Rev. B 1976, 13, 5188-5192.

62. Fischer, T.H.; Almlof, J.J. General methods for geometry and wave function optimization. J. Phys. Chem. 1992, 96, 9768-9774.

63. Pearson, W.B. A Handbook of Lattice Spacings and Structures of Metals and Alloys; Pergamon Press: New York, NY, USA, 1967; Volume 2.

64. Bauer, E. Epitaxy of metals on metals. Appl. Surf. Sci. 1982, 11/12, 479-494.

65. Tersoff, J. Surface-Confined Alloy Formation in Immiscible Systems. Phys. Rev. Lett. 1995, 74, 434-437.

66. Vitos, L.; Ruban, A.V.; Skriver, H.L.; Kollar, J. The surface energy of metals. Surf. Sci. 1998, 411, 186-202.

67. Tyson, W.R.; Miller, W.A. Surface free energies of solid metals: Estimation from liquid surface tension measurements. Surf. Sci. 1977, 62, 267-276.

68. De Boer, F.R.; Boom, R.; Mattens, W.C.M.; Miedema, A.R.; Niessen, A.K. Cohesion in Metals; North-Holland: Amsterdam, The Netherlands, 1988.

69. Campbell, C.T. Bimetallic Surface Chemistry. Annu. Rev. Phys. Chem. 1990, 41, 775-837.

70. Sinhg-Miller, N.E.; Marzari, N. Surface energies, work functions, and surface relaxations of low index metallic surfaces from first-priniples. Phys. Rev. B 2009, 80, 2354071-2354079.

71. Da Silva, J.L.F.; Stampft, C.; Scheffler, M. Converged properties of clean metal surfaces by all electron first-principles calculations. Surf. Sci. 2006, 600, 703-715.

72. Kittel, C. Introduction to Solid State Physics, 7th ed.; Wiley: New York, NY, USA, 1996.

73. Kitchin, J.R.; Norskov, J.K.; Barteau, M.A.; Chen, J.G. Modification of the surface electronic and chemical properties of $\operatorname{Pt}(111)$ by subsurface $3 d$ transition metals. J. Chem. Phys. 2004, 120, 10240-10246.

74. Schminka, L.; Harl, J.; Stroppa, A.; Grueneis, A.; Marsman, M.; Mittendorfer, F.; Kresse, G. Accurate surface and adsorption energies from many-body perturbation theory. Nat. Mater. 2010, 9, 741-744.

75. Behafarid, F.; Ono, L.K.; Mostafa, S.; Croy, J.R.; Shafai, G.; Hong, S.; Rahman, T.S.; Bare, S.R.; Cuenya, B.R. Electronic properties and charge transfer phenomena in Pt nanoparticles on $\gamma-\mathrm{Al}_{2} \mathrm{O}_{3}$ : Size, shape, support, and adsorbate effects. Phys. Chem. Chem. Phys. 2012, 14, 11766-11779.

76. Liu, X.; Sui, Y.; Duan, T.; Meng, C.; Han, Y. CO oxidation catalyzed by Pt-embedded graphene: A first-principles investigation. Phys. Chem. Chem. Phys. 2014, 16, 23584-23593.

77. German, E.; Lopez-Corral, I.; Pirillo, S.; Juan, A.; Brizuela, G. A DFT study of cyclopropane adsorption on Pt(111). Electronic structure and bonding. Appl. Surf. Sci. 2014, 303, 324-330.

78. PL-Grid. Available online: http://www.plgrid.pl/en (accessed on 27 January 2015).

(C) 2015 by the authors; licensee MDPI, Basel, Switzerland. This article is an open access article distributed under the terms and conditions of the Creative Commons Attribution license (http://creativecommons.org/licenses/by/4.0/). 